\title{
Diversity in one dimension alongside greater similarity in others: evidence from FP7 cooperative research teams
}

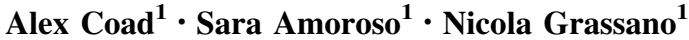

Published online: 23 February 2017

(C) The Author(s) 2017. This article is published with open access at Springerlink.com

\begin{abstract}
Although diversity between team members may bring benefits of new perspectives, nevertheless, what holds a team together is some degree of similarity. We theorise that diversity in one dimension is traded off against diversity in another. Our analysis of collaborative research teams that received FP7 funding presents robust results that indicators of diversity in several dimensions-diversity of organizational form (universities, firms, etc.), diversity in nationality, and inequality in project funding share - are negatively correlated with each other.
\end{abstract}

Keywords Diversity · Collaborative teams · FP7 research funding

JEL Classification $\mathrm{O} 32 \cdot \mathrm{O} 38$

"Birds of a feather flock together"

"Opposites attract"

[popular proverbs]

\section{Introduction}

Boosting open innovation and improving knowledge transfer between research institutions and third parties such as industry and civil society organizations is one of the key areas of science and technology policy in Europe. One of the main instruments to foster knowledge transfer between research institutions and industry across Europe has been the promotion

Sara Amoroso

sara.amoroso@ec.europa.eu

Alex Coad

alexander.coad@ec.europa.eu

Nicola Grassano

nicola.grassano@ec.europa.eu

1 Joint Research Centre, European Commission, Calle Inca Garcilaso 3, 41092 Seville, Spain 
of research consortia between firms, universities, research centres, and public entities through the Framework Programmes (FP) for research and technological development. However, knowledge transfer within a group hinges critically on trusting social relations between team members (Alexopoulos and Buckley 2013).

In this regard, an important question relates to how different individuals and actors can be brought together-despite their heterogeneous backgrounds, cultures and perspectives - to form an effective research team. When it comes to the issue of cooperative teams, which of the two opening proverbs is more true? Are project teams composed of members that are different or similar? The answer, as the reader might have guessed, is probably both. Researchers have reconciled these two opening proverbs by showing that there are curvilinear effects of diversity on team formation and performance-that too much diversity (in terms of one particular variable) might become a liability above a certain threshold, giving rise to an inverted-U-shaped effect of team diversity on performance (e.g. Huang and Chen 2010; Von Raesfeld et al. 2012; Oerlemans et al. 2013). Hence, diversity of teams is characterized by a 'too much of a good thing' effect (Pierce and Aguinis 2013). However, we depart from the unidimensional 'too much of a good thing' effect and take a different approach to reconciling the two opening proverbs. We shed new light on the phenomenon by showing that diversity in one dimension is negatively related to diversity in other dimensions. ${ }^{1}$ We therefore contribute to the literature on diversity which, previously, has focused on individual dimensions of diversity one at a time, without considering how they might interact.

More specifically, focusing on a rich data source on FP7 European collaborative research projects, we present new insights on how a high level of diversity in terms of type of cooperating organizations (firms, universities, research organizations, etc.) is associated with less diversity in other dimensions such as the degree of internationalization and the diversity of cost share among the members of a research consortium. Our theoretical predictions receive robust support. Pairwise correlations show that a higher level of diversity for one of these indicators is associated with a lower level of diversity for the other indicators.

The remainder of this paper is outlined as follows. Section 2 contains the theoretical background and derives our hypotheses. Section 3 presents our database and contains some summary statistics on our diversity indicators. Section 4 contains the empirical analysis. Section 5 concludes.

\section{Theoretical background}

Diversity is a multidimensional and multicultural construct. Teams can be diverse in many ways: different educational backgrounds, different genders, different ethnicities, different ages, different nationalities, different levels of industry experience, etc. Previous research looked at how team performance depended on team diversity in specific dimensions. The early literature sought to answer whether diversity is good or bad for performancewhether it be diversity in education or gender or experience etc.

Diversity can have a positive effect on team performance outcomes such as creativity, innovation and problem-solving quality, if the team members do not all possess duplicates of the same skill-sets, but complement each other (Cox and Blake 1991). Diversity of perspectives

\footnotetext{
1 To illustrate in layman's terms, one might have more patience for the eccentricities of family members than similar eccentricities from friends or colleagues-simply because family members are otherwise very similar in a large number of ways. Another example would be that age differences between team members are easier to accept if the team members have otherwise similar backgrounds.
} 
is associated with a lower emphasis on conforming to the norms of the past, which can improve the level of creativity (Cox and Blake 1991). In the context of research teams, actors often seek a niche for their own work and seek to differentiate themselves (Dahlander and McFarland 2013), while accessing the skills of others through the formation of a collaborative research team. Specialization of individuals in the context of a diverse research team can help avoid the costs of redundant ideas and unnecessary knowledge overlap, while the partners pool their skills together to enhance their team capabilities at problem-solving.

However, too much diversity can mean that team members lack the common tacit knowledge that facilitates communication, which makes it challenging to comprehend one another. For example, too much international diversity can lead to social categorization, which hinders information use and knowledge transfer (Dahlin et al. 2005). Functional background diversity among team members can drive task conflict, while race and tenure diversity can lead to emotional conflict (Pelled et al. 1999). Excessive diversity can also lead to reduced interpersonal liking and lower psychological commitment (Lau and Murnighan 2005). Actors may therefore seek out similar actors to quickly winnow the field of potential collaborators (Dahlander and McFarland 2013). Similarity engenders a sense of connection and belonging, a common ground and mutual interest, and a greater sense of interpersonal understanding and security (Dahlander and McFarland 2013), while ties between nonsimilar individuals may be more time-consuming to maintain, may lead to more conflicts, and are more likely to be dissolved (McPherson et al. 2001).

Early investigations applied linear regression models to see if the relationship was positive or negative (Bantel and Jackson 1989; Ucbasaran et al. 2003; Chandler et al. 2005; Chowdhury 2005; Foo et al. 2005; Amason et al. 2006; Vanaelst et al. 2006).

The next generation of investigations found that the relationship was curvilinear - that a moderate amount of diversity was good, but that above a certain threshold the gains to diversity were smaller than the costs (Dahlin et al. 2005; Horwitz and Horwitz 2007; Ostergaard et al. 2011).

Our key critique of the literature on team diversity is that the different indicators of diversity are assumed to operate independently of each other. Each dimension is usually considered in isolation. An exception would be the 'faultlines' approach (e.g. Lau and Murnighan 2005), which examines whether sub-groups might break away from their larger groups if they have different attributes in more than one dimension-such as a team composed of young Hispanic women and old Caucasian men. Our approach is different, because we investigate how diversity in one dimension is compensated for by lower levels of diversity in other dimensions. We therefore contribute to the literature by taking a new approach towards conceptualizing diversity, as well as presenting supporting evidence. We argue that diversity among partners in a research team is costly, in terms of cognitive effort and team management, and that a research team will compensate for high levels of diversity in one domain by reverting to lower levels of diversity on other domains.

Our paper can help to explain why literature reviews and meta-analyses suggest that the previous investigations into diversity in entrepreneurial teams and management teams have provided mixed and inconclusive results (Webber and Donahue 2001; Harrison and Klein 2007; Horwitz and Horwitz 2007) - i.e. because their models of diversity neglected the interdependence of these dimensions of diversity, and were thus mis-specified. Including several different indicators of diversity in a linear regression model (where the dependent variable is team performance) will not reveal the relationships that exist between the diversity indicators themselves. Instead, we go beyond the usual finding that the performance effects of diversity are likely to be curvilinear within individual dimensions of diversity (as emphasized by the existing literature surveyed above), and instead show that the different dimensions of diversity should not be taken as independent but that they are inter-related. 
Our approach has implications for how team diversity should be conceptualized. In the context of research teams, for example, our approach would predict that interdisciplinary research teams will have less diversity in terms of country and organizational form of its participants than a single-discipline research team, because the diversity in disciplinary focus is compensated for by reduced diversity in the other domains. Similarly, collaborative research projects that include universities, firms, and other organizational forms would probably be more likely to be located in the same country or region, to better manage the difficulties in communication that arise when agents are heterogeneous (in terms of organizational form). Our approach would also predict that, for more academic projects that include only universities (as organizational forms), these projects are more likely to be international.

We therefore posit a broad hypothesis:

Hypothesis 1: Diversity in one dimension is observed alongside greater similarity in others.

More specifically, Hypothesis 1 is tested in the context of our dataset, where team diversity is measured in terms of organizational form (university, firm, etc.), number of countries, and members' share of the total project's cost. These are among the most salient dimensions of member diversity regarding the formation of collaborative research teams in the FP7 scheme. For example, diversity in terms of organizational form might complicate the communication between partners who potentially have different goals and objectives (e.g. if firms seek the profitable commercialization of innovations while universities pursue scientific excellence). Nationality is a core part of an individual's identity (Dahlin et al. 2005). Diversity in terms of the nationalities of the members exposes the research team to different norms and beliefs, possible difficulties in communicating across cultural categories (Dahlin et al. 2005), as well as higher costs of coordination and management. Diversity in terms of members' cost shares might be problematic if the team members have different roles and varying degrees of status, importance and centrality in the research team.

We hypothesize that these different dimensions of diversity will be interdependent. A high level of diversity in terms of organizational form might therefore need to be compensated for in terms of less diversity in terms of participant countries (to ensure that participants have a shared tacit knowledge base and cultural background to facilitate communication), as well as less diversity in terms of member's share of total project cost (i.e. where less diversity in terms of project shares means that funding is relatively evenly distributed, with participants having roles in the project that are more equally matched). We therefore investigate the following sub-hypotheses:

Hypothesis 1a Diversity in terms of organizational form is negatively correlated with diversity in terms of participant countries

Hypothesis 1b Diversity in terms of organizational form is negatively correlated with diversity in terms of members' share of the total project's cost

Hypothesis 1c Diversity in terms of participant countries is negatively correlated with diversity in terms of members' share of the total project's cost

\section{Data}

\subsection{Database description}

While most research into team diversity and performance has focused on top management teams (e.g. Bantel and Jackson 1989) or entrepreneurial new venture teams (e.g. Steffens 
et al. 2012; Kaiser and Müller 2015), we focus on collaborative research teams. Collaboration is increasingly important for scientific research (Jones et al. 2008) as well as for innovation and technological development (Hoekman et al. 2013), and there is lots of policy interest in collaborative research projects. However, to date, not much research has focused on the diversity of members of collaborative research teams.

Our data covers the universe of successful applications to the European Union's Seventh Framework Programme for Research and Technological Development (FP7), which was set up to provide funding for research and technological development in the European Research Area. The Framework Programmes for Research and Technological Development are medium-term planning instruments for research and innovation created by the European Commission The first Framework Programme had a budget of about $€ 3$ bn, and began in 1984 and lasted until 1987. The following Framework Programmes had increasingly large budgets, with $€ 15$ bn for FP5, €18bn for FP6, and over $€ 50$ bn for FP7 (Rodriguez et al. 2013). FP7 has now been replaced by "Horizon 2020" (previously named FP8), which is set to run from 2014 to 2020.

FP7 was the EU's main policy instrument for funding European research over the period 2007-2013. The majority of FP7 funds were allocated to the block of activities labelled "Cooperation," that is dedicated for the purposes of the funding of collaborative research projects. This programme was subsequently divided into 10 thematic areas, the largest of which were Information \& Communication Technologies ( $€ 9.11$ bn), Health ( $€ 6.05$ bn), and Transport (including aeronautics; $€ 4.18 b n$ ) (European Commission 2006).

Each project has a single coordinator. Coordinators are the legal entities that are in charge of the contracts both in legal terms and in scientific terms, since they are 'legally' responsible in the eyes of the European Commission for the successful management of the project (Maggioni et al. 2007).

Our data focuses on collaborative research teams that successfully applied for FP7 funding. Teams that did not get FP7 funding are not included in our dataset. To the extent that our hypotheses require an indicator of team performance, our indicator of performance would be that all the teams in our database were successful in obtaining FP7 funding, because only a small share of applications will succeed. However, considering that FP7 funding was awarded on many criteria, receipt of FP7 funding (and hence inclusion in our dataset) is a potentially opaque indicator of performance (although it can also be argued that survival and success in business environments is an opaque and multifaceted criterion). Nevertheless, given our focus on the role of diversity in the structure of collaborative teams, we argue that the performance outcomes are of secondary importance for our present purposes. Indeed, focusing on the composition of teams and investigating the frequency of teams that are formed, without necessarily linking this to team performance is, in itself, a worthwhile avenue for research (Ruef et al. 2003).

An advantage of our dataset is the comprehensive coverage of successful FP7 applications, which means that we have a large number of observations. Our raw data contains cooperative teams of vastly different sizes-from one or two members to over a hundred (see Appendix 1). However, having a large number of observations in our dataset will allow us to crucially narrow down our scope to focus on teams composed of the same number of members. In our analysis, we focus exclusively on teams with 7-9 participants, for several reasons. First, Appendix 1 shows that being in a team of size 8 is the most frequently-observed outcome for team members (if we ignore 'teams' of one or two members), closely followed by teams of size 7 and 9 . Our relatively large sample compares favourably to previous investigations of entrepreneurial teams that have samples of 200 or lower (see the review in Coad and Timmermans 2014 Table 1). Focusing on teams of 7, 8 or 9 individuals will also be relevant for other research contexts, such as top management 
Table 1 Frequencies of types of organizational form

\begin{tabular}{lll}
\hline & Number & Frequency (\%) \\
\hline Higher or secondary education establishments (i.e. 'universities') & 8397 & 34.2 \\
Private commercial (i.e. 'firms') & 9200 & 37.5 \\
Public body & 655 & 2.7 \\
Research organisations & 5621 & 22.9 \\
Other & 655 & 2.7 \\
Total number of team members & 24,528 & 100 \\
\hline
\end{tabular}

For collaborative projects of teams with $\mathrm{N}=7, \mathrm{~N}=8$ or $\mathrm{N}=9$

teams that might be composed of a similar number of individuals. Second, a practical reason is that, unlike smaller team sizes of e.g. 2 or 3 participants, a team size of 7-9 members is sufficient to allow for indicators of diversity (such as integer counts or Herfindahl indices) to cover an interesting range of possible values. Third, restricting all of our observations to teams with a similar number of participants (between 7 and 9 members) will mean that our observations are closely comparable. Indeed, diversity indicators are not invariant to the number of team members (Coad and Timmermans 2014), and we wish to avoid any spurious results that might emerge from comparing diversity indicators from teams of very different sizes.

Our data consists of collaborative research teams that obtained FP7 research funding in the time window 2007-2013. Each projects then lasted up to 6 years. Although we cannot rule out that the same collaborative team participated in two subsequent projects during this time window, nevertheless for simplicity we treat our dataset as a cross-section.

\subsection{Indicators of diversity}

\subsubsection{Diversity of organizational form}

FP7 participants can have a variety of different organizational forms: university, private firm, public body, or Public Research Organization. Table 1 shows that the two most common types of organizational form are universities (34.2\% of cases) and firms (37.5\% of cases). As our indicator of the diversity of organizational forms, we simply take an integer count of the number of distinct organizational forms (Stirling 2007). This simple indicator is easy to understand, and it is an informative indicator of diversity for our purposes because our observations relate to teams of the same size. The minimum value is 1 (if all team members are of the same organizational form, e.g. all are universities or all are private firms) up to a possible maximum of 5.

\subsubsection{International diversity}

This indicator relates to the number of different countries represented by the project members. (Countries refer to the organizations involved rather than the nationalities of the individuals involved.) The number of countries represented is potentially large: although there are restrictions on the nationality of the FP7 project coordinators (which should be European nationals, although there are some exceptions), nevertheless non-coordinating members can come from any country in the world. Again, this is a simple integer count variable of the number of distinct countries. The minimum value is 1 and the maximum possible value is 9 . 


\subsubsection{Project cost diversity}

Collaborative teams vary in terms of their share of the total project cost. As a further indicator of team member heterogeneity, we analyse the information on the share of the total project cost that is distributed to each project member. The project cost share is a continuous variable that ranges from 0 (for a very large number of members with an atomistic share each) to 1 (where one member basically accounts for all of the project cost). Instead of taking an integer count variable (as before), we take the Herfindahl index which is a meaningful indicator of diversity that has been used in previous research (e.g. Foo et al. 2005; Beckman et al. 2007). We calculate the Herfindahl-Hirschman index (HHI) as follows (Beckman et al. 2007, p157):

$$
H H I=\sum_{i=1}^{n} P_{i}^{2}
$$

where the number of project members $\mathrm{n}=7,8$, or 9 and $P_{\mathrm{i}}$ is the project cost share. Our indicator of project cost diversity based on the HHI index is similar to the two previous diversity indicators described above, in that low scores correspond to cases of low diversity (i.e. where all members get the same cost share) whereas large scores correspond to cases of high diversity (i.e. where there is much inequality in the project cost shares across members, with one member getting a large share).

Table 2 provides summary statistics for our diversity indicators. The first two indicators are discrete while the third is continuous. Collaborative research teams vary considerably according to these three indicators.

We also tried to investigate diversity according to disciplinary theme, to investigate the structure of interdisciplinary teams. However, in our dataset, all members of a project are listed under the same project-specific theme, that is the same for all project members. Therefore we could not investigate heterogeneity in research themes. Relatedly, one might wish to investigate diversity according to industry affiliations, but upon closer reflection, the problem here would be that industry affiliations are only allocated to firms and not to other organizational forms (such as universities or public research organizations).

\subsection{Control variables}

In our analysis of the diversity of collaborative teams, we want to be careful about pooling together teams of different sizes. This way, each collaborative team in our sample has a similar range of possible values for the diversity indicators, and are also closely comparable because of their similar size. More specifically, firms in our sample consist of either 7, 8 or 9 partners. We therefore include dummy variables for the purposes of controlling for heterogeneity in group size (e.g. Pelled et al. 1999).

Table 2 Summary statistics on our diversity indicators

\begin{tabular}{llllll}
\hline & Mean & Std. Dev. & Median & Min & Max \\
\hline No. organizational forms & 2.834 & 0.747 & 3 & 1 & 5 \\
No. countries & 5.259 & 1.332 & 5 & 1 & 9 \\
HHI project cost share & 0.188 & 0.071 & 0.169 & 0.113 & 0.891 \\
\hline
\end{tabular}

For collaborative projects of teams with $\mathrm{N}=7, \mathrm{~N}=8$ or $\mathrm{N}=9.3072$ observations for 3072 teams 
In subsequent regressions, we include some control variables that are observed at the project-level (and not at the team-member level). First, we control for the potential role of the total project cost on team diversity, because projects with larger budgets might be more supportive environments for diversity between team members (e.g. well-funded projects might allow diverse team-members to come to an agreement more readily than if they are under financial pressure). Total project cost has a mean of 3,134,319 EUR and a standard deviation of 2,113,901 for our sample of teams. Second, we control for the project duration, because projects with longer duration might be more amenable for higher levels of diversity (if team members are not pressurized by time constraints to reach agreements with their diverse collaborators). Total project duration has a mean of 35.99 months and a standard deviation of 9.97 in our sample of teams. Appendix 3 describes the main variables used in the analysis.

\section{Analysis}

We begin with a correlation analysis, where we compare indicators of diversity in a pairwise manner, without seeking to explain any one particular indicator (by taking it as dependent variable). We follow with multivariate regressions, that can include all three indicators of diversity in the same analytical model, as well as some control variables.

\subsection{Correlation analysis}

Table 3 presents the correlation coefficients for the relationships between the different indicators of diversity. In most cases, the Pearson correlation coefficients (lower triangular cells) are significantly negative. Further results from Spearman's rank correlation coefficients (that are more robust to outliers and to non-Gaussian-distributed variables) are also usually significantly negative (upper triangular cells). The exception is the relationship between number of organizational forms and number of countries, for which the correlation is far from the usual thresholds of statistical significance.

Appendix 2 provides graphical evidence to complement the correlation analysis in Table 3. Appendix 2 shows that the indicators of diversity are generally negatively correlated between themselves (with the exception being the relationship between number of organizational forms and number of countries). Although collaborative research teams are heterogeneous, and do not all lie close to the line of best fit, nevertheless the general tendency is that there is a negative relationship between diversity in one domain and diversity in another.

Table 3 Correlation matrix for the relationships between the three different types of diversity

\begin{tabular}{llll}
\hline & No. Org. forms & No. countries & HHI project cost share \\
\hline No. org. forms & 1 & $\mathbf{- 0 . 0 0 4 6}$ & $\mathbf{- 0 . 1 2 7 8}$ \\
& & 0.7973 & 0.0000 \\
No. countries & $\mathbf{- 0 . 0 1 3 3}$ & 1 & $\mathbf{- 0 . 2 2 9 8}$ \\
HHI project cost share & 0.4605 & & 0.0000 \\
& $\mathbf{- 0 . 0 6 5 7}$ & $\mathbf{- 0 . 1 5 5 4}$ & 1 \\
\hline
\end{tabular}

Lower triangular cells: Pearson correlation coefficients (in bold), and associated $p$ values

Upper triangular cells (and in italics): Spearman's rank correlation coefficients (in bold), and associated $p$ values. 3072 observations in all cases, corresponding to one observation per team 
Taken together, we observe negative pairwise correlations between diversity of organizational forms and project cost shares, and between diversity of number of countries and project cost shares (and a non-significant correlation between diversity of organizational forms and diversity of participating countries). At this stage, we find support for Hypotheses $1 \mathrm{~b}$ and $1 \mathrm{c}$, but doubts about Hypothesis 1a.

Robustness of the results was verified by removing the $1 \%$ observations at both extremes of HHI project cost share (which is the only approximately continuous variable among the three). The correlations are negative and significant, except (as before) in the case of diversity of organizational forms and diversity of countries.

\subsection{Multivariate regressions}

We pursue our investigation by applying multivariate regressions, where we can include all three indicators of diversity in the same analytical model, as well as controlling for the potentially confounding influence of other variables.

The regression results reported here take the diversity of organizational forms as the dependent variable (rather than any of the two other diversity indicators), because the skewness and kurtosis statistics show that it is the diversity indicator that is closest to the Gaussianity requirement for least-squares estimation. (In further robustness analysis, however, we verify that our main results hold when taking the two other diversity indicators as the dependent variable.) Regressions are estimated using Ordinary Least Squares, and for extra precision in our inference, standard errors are obtained after 500 bootstrap replications.

Table 4 shows the regression results. Each of the three diversity indicators are significantly negatively related to each other, across two different regression specifications (that vary according to the inclusion of control variables). Table 4 therefore offers support to Hypotheses 1a, 1b and 1c.

In both regression specifications, we observed a significant negative correlation between diversity in one domain, and diversity in another. This finding is reminiscent of the negative correlation between international diversity and institutional diversity that is visible in in the study of Pandza et al. (2011, Fig. 4) on FP6 data on nanotechnology, although the authors do not comment in depth on this negative correlation, or provide any theoretical interpretation.

\section{Conclusion}

We began by theorising about the benefits and drawbacks of diversity. If a team is diverse in one domain, it might seek to compensate by having greater similarity in other domains. For example, interdisciplinary teams might seek similarity in other dimensions such as age, cultural factors, or geographical base. Our paper therefore carries implications for the choice of innovation partner-if the partner is very different in certain aspects, then it may be prudent to seek similarity in others.

Previous research found curvilinear effects-positive effects of diversity on performance for low values of diversity, but negative effects for high values of diversity. Hence, there exists an optimum amount of diversity, found at the inflexion point on the curve of performance across the range of diversity. This can be generalized as the 'too much of a good thing' effect (Pierce and Aguinis 2013). In contrast to the previous literature on the optimal amount of diversity in any single diversity dimension, our results suggest that this optimum amount of diversity depends on the amount of diversity in other dimensions. More specifically, we suggest that the 
Table 4 Regression results with diversity of organizational forms as the dependent variable

Ordinary Least Squares regressions. Team sizes of 7,8 and 9 team members are pooled together in the analysis. Standard errors (in parentheses) are obtained after 500 bootstrap replications

Key to significance levels: $* * * p<0.01, * * p<0.05$, $* p<0.1$
(1)

(2)

\begin{tabular}{lll}
\hline No. countries & $-0.0343 * * *$ & $-0.0283 * *$ \\
& $(0.0116)$ & $(0.0116)$ \\
HHI project & $-0.480 *$ & $-0.551 * *$ \\
cost share & $(0.263)$ & $(0.269)$ \\
Dummy: 7 members & $-0.0821 * *$ & $-0.0771 * *$ \\
& $(0.0331)$ & $(0.0333)$ \\
Dummy: 9 members & $0.182 * * *$ & $0.175 * * *$ \\
Project cost (in logs) & $(0.0334)$ & $(0.0340)$ \\
& & $0.0694 * *$ \\
Project & & $(0.0273)$ \\
duration & & $-0.00742 * * *$ \\
Constant & & $(0.00193)$ \\
& $3.074 * * *$ & $2.301 * * *$ \\
Observations: number of groups & 3072 & $(0.388)$ \\
R-squared (adj) & 0.024 & 3072 \\
\hline
\end{tabular}

optimum amount of diversity on one dimension is negatively related to the level of diversity in another dimension. In the context of FP7 collaborative research teams, we observe negative relationships between the level of diversity in terms of members' organizational form, the diversity of country backgrounds, and the diversity of members' share of the project cost (an indicator of their status and centrality in the research project). Our analysis shows that all of our hypotheses are supported, and our results are robust across regression specifications.

Our empirical investigation is not without limits. First, our dataset does not include team-level performance outcomes (beyond the observation that our data focuses exclusively on successful FP7 applications). Second, a possible limitation of our dataset concerns whether 'political' considerations (e.g. whether evaluators look favourably on projects that include members from less developed European countries) might influence team formation and funding chances, beyond purely 'meritocratic' concerns. Third, our analysis is undertaken on data that is essentially cross-sectional in structure-it would be interesting to investigate the dynamics of team composition and diversity (e.g. some individual characteristics cannot be changed (e.g. gender, ethnicity) while others change automatically (age) and still others can be manipulated by the individual (e.g. experience, preferences or team roles)). It is therefore worth investigating the effect of time on team diversity and team performance (Steffens et al. 2012; Kaiser and Müller 2015). Do teams become more diverse over time? Do individuals make efforts to compensate, and seek to 'specialize' and complement each other in certain dimensions, thus altering the teamlevel diversity over time? Future work could investigate these issues in more detail.

Future work could use data from other contexts, such as the startup of commercial new ventures. With regards to FP7 funding, future work might fruitfully compare recipients of FP7 funding with research teams that applied but were not successful in obtaining funding, to see if the characteristics of successful teams are different from those of unsuccessful applicants. Future work might also investigate the effects of diversity on more conventional indicators of team performance, when 'excessive' or 'disproportionate' diversity in one dimension can be traded off against increased similarity in other dimensions, to boost overall performance. Finally, future research might also focus on the interdisciplinary nature of cooperative teams (because our data did not allow us to investigate the role of diverse disciplinary backgrounds within research projects). 
To conclude, we suggest a new approach for thinking about the costs and benefits of diversity for team structure and performance. While previous papers that highlighted the curvilinear relationship between diversity and performance (with benefits eventually leading to higher costs as diversity increases), our results suggest that high levels of diversity in one dimension need not necessarily be a liability if they can be offset by sufficient similarity in other dimensions. An implication for research teams that are in the process of choosing partners, and for the design of work groups more generally, could be that they should first choose which dimensions of diversity are more important for them, in anticipation of the possible compensation of a high level of diversity in one domain by a lower level of diversity in other domains. For example, a research team that prioritizes diversity in terms of organizational forms of the team members should be aware that the research team might have a lower expected level of diversity in terms of country representation. In the context of pan-European FP7 collaborative research projects, one possible strategy for enhancing the inclusion of lagging regions in international collaborative teams (c.f. Hoekman et al. 2013) is to ensure that they are otherwise similar to their team partners (in terms of project share, organizational form, and possibly also in other dimensions).

Acknowledgements We are grateful to Andries Brandsma, Mathieu Doussineau, Koen Jonkers, Bettina Mueller, Bram Timmermans, and also to the editor Al Link and two anonymous reviewers for many helpful comments on an earlier draft. Any remaining errors are ours alone. The views expressed are purely those of the authors and may not in any circumstances be regarded as stating an official position of the European Commission.

Open Access This article is distributed under the terms of the Creative Commons Attribution 4.0 International License (http://creativecommons.org/licenses/by/4.0/), which permits unrestricted use, distribution, and reproduction in any medium, provided you give appropriate credit to the original author(s) and the source, provide a link to the Creative Commons license, and indicate if changes were made.

\section{Appendix 1}

See Fig. 1.

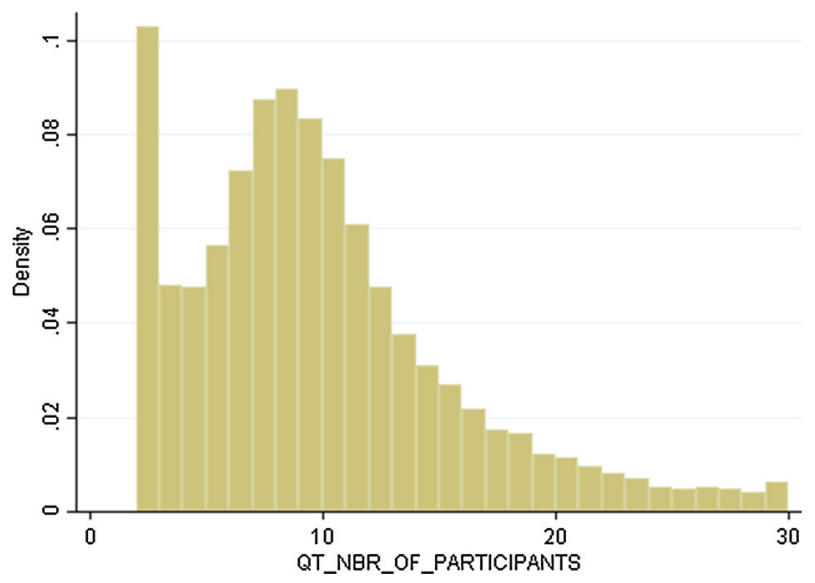

Fig. 1 Histogram of the frequencies of members of different team sizes of FP7 collaborative projects. Beyond the peak at 2 participants, there is a second peak at 8 participants 


\section{Appendix 2}

See Fig. 2.
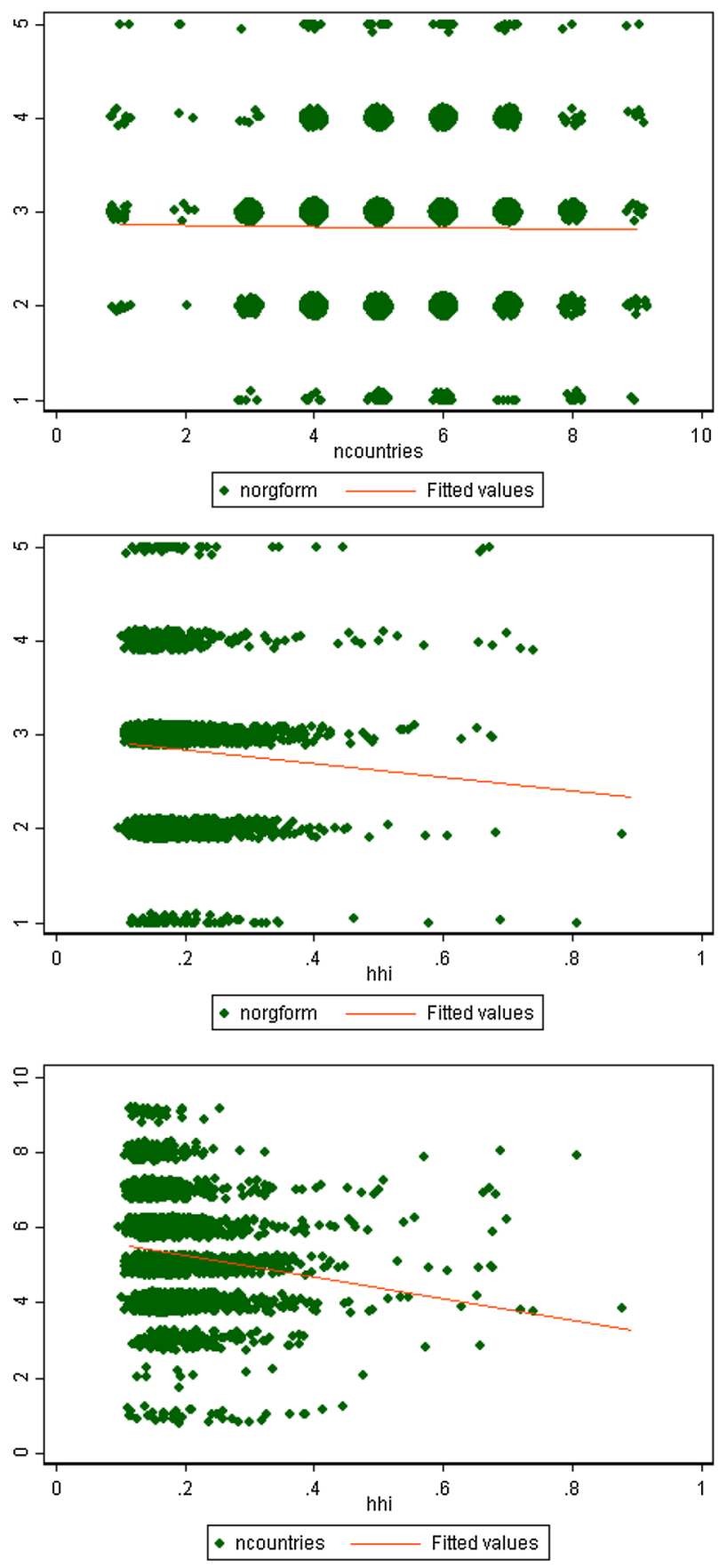
4Fig. 2 Pairwise scatterplots of the relationships between diversity indicators, with a linear fit. Scatterplots with the negatively-sloped linear fit for the correlations between number of organizational forms and number of countries (top); number of organizational forms and project cost HHI index (centre); and number of countries and project cost HHI index (bottom). Scatterplots drawn using Stata 14's “jitter” option, which adds spherical random noise to the data before plotting to avoid having datapoints plotted on top of each other

\section{Appendix 3: FP7 database}

The database includes variables at different levels of aggregation—such as the project level (e.g. identity of the coordinator) or the participant level (identity of the individual participant). While some variables are present in the initial dataset, other variables were constructed from the initial data to gain further insights into the composition of cooperative networks. Table 5 below contains a description of the variables used in the analysis.

Table 5 Description of the main variables

\begin{tabular}{ll}
\hline Role on project & $\begin{array}{c}\text { Coordinator vs non-coordinating participant on the project. Each project has } \\
\text { one coordinator } \\
\text { Total cost claimed by a member (coordinator or participant) for their 'slice } \\
\text { of the pie', i.e. their share of the project's activity. A natural logarithm is } \\
\text { sometimes taken for this variable } \\
\text { Total contribution made by the EC to a particular project member's cost. A } \\
\text { natural logarithm is sometimes taken for this variable }\end{array}$ \\
$\begin{array}{l}\text { EC contribution to a } \\
\text { member's activity }\end{array}$ & $\begin{array}{l}\text { Total cost of the project, before it is divided between project members. A } \\
\text { natural logarithm is sometimes taken for this variable }\end{array}$ \\
Total project cost & $\begin{array}{c}\text { Total contribution made by the EC to a particular project's total cost. A } \\
\text { natural logarithm is sometimes taken for this variable }\end{array}$ \\
EC contribution to the total \\
project cost \\
Cost of member's activity, divided by the total project cost \\
Number of participants \\
$\begin{array}{l}\text { Number of distinct participating entities (not individuals) on the project } \\
\text { Project duration } \\
\text { Country }\end{array}$ \\
$\begin{array}{l}\text { Project duration, in months } \\
\text { Organization type }\end{array}$ \\
$\begin{array}{l}\text { Country where the participating entity is located } \\
\text { Organization type, which is one of the following: Higher or secondary } \\
\text { education est. (sometimes relabelled as 'university'); Private commercial } \\
\text { (sometimes relabelled as 'firm'); Public body excluding research and }\end{array}$ \\
education (sometimes relabelled as 'public body'); and Research \\
organizations; as well as some residual categories ("Not defined", \\
"Other", and "Private commercial SME" (1 project only))
\end{tabular}

\section{References}

Alexopoulos, A. N., \& Buckley, F. (2013). What trust matters when: The temporal value of professional and personal trust for effective knowledge transfer. Group and Organization Management, 38(3), 361-391.

Amason, A. C., Shrader, R. C., \& Thompson, G. H. (2006). Newness and novelty: Relating top management team composition to new venture performance. Journal of Business Venturing, 21, 125-148.

Bantel, K., \& Jackson, S. (1989). Top management and innovations in banking: Does the composition of the top team make a difference? Strategic Management Journal, 10, 107-124.

Beckman, C. M., Burton, M. D., \& O'Reilly, C. (2007). Early teams: The impact of team demography on VC financing and going public. Journal of Business Venturing, 22, 147-173.

Chandler, G. N., Honig, B., \& Wiklund, J. (2005). Antecedents, moderators, and performance consequences of membership change in new venture teams. Journal of Business Venturing, 20(5), 705-725.

Chowdhury, S. (2005). Demographic Diversity for building an effective entrepreneurial team: is it important? Journal of Business Venturing, 20, 727-746. 
Coad, A., \& Timmermans, B. (2014). Two's Company: Composition, Structure and Performance of Entrepreneurial Pairs. European Management Review, 11(2), 117-138.

Cox, T. H., \& Blake, S. (1991). Managing cultural diversity: Implications for organizational competitiveness. Academy of Management Executive, 5(3), 45-56.

Dahlander, L., \& McFarland, D. A. (2013). Ties that last tie formation and persistence in research collaborations over time. Administrative Science Quarterly, 58(1), 69-110.

Dahlin, K. B., Weingart, L. R., \& Hinds, P. J. (2005). Team diversity and information use. Academy of Management Journal, 48(6), 1107-1123.

Foo, M. D., Wong, P. K., \& Ong, A. (2005). Do others think you have a viable business idea? Team diversity and judges' evaluation of ideas in a business plan competition. Journal of Business Venturing, 20, 385-402.

Harrison, D. A., \& Klein, K. J. (2007). What's the difference? Diversity constructs as separation, variety, or disparity in organizations. Academy of Management Review, 32(4), 1199-1228.

Hoekman, J., Scherngell, T., Frenken, K., \& Tijssen, R. (2013). Acquisition of European research funds and its effect on international scientific collaboration. Journal of Economic Geography, 13, 23-52.

Horwitz, S. K., \& Horwitz, I. B. (2007). The effects of team diversity on team outcomes: a meta-analytic review of team demography. Journal of Management, 33(6), 987-1015.

Huang, Y. F., \& Chen, C. J. (2010). The impact of technological diversity and organizational slack on innovation. Technovation, 30(7), 420-428.

Jones, B. F., Wuchty, S., \& Uzzi, B. (2008). Multi-university research teams: Shifting impact, geography, and stratification in science. Science, 322(5905), 1259-1262.

Kaiser, U., \& Müller, B. (2015). Team heterogeneity and its development over time. Small Business Economics, 45(4), 787-804.

Lau, D. C., \& Murnighan, J. K. (2005). Interactions within groups and subgroups: the effects of demographic faultlines. Academy of Management Journal, 48(4), 645-659.

Maggioni, M. A., Nosvelli, M., \& Uberti, T. E. (2007). Space versus networks in the geography of innovation: A European analysis. Papers in Regional Science, 86(3), 471-494.

McPherson, M., Smith-Lovin, L., \& Cook, J. (2001). Birds of a feather: Homophily in social networks. Annual Review of Sociology, 27, 415-444.

Oerlemans, L. A., Knoben, J., \& Pretorius, M. W. (2013). Alliance portfolio diversity, radical and incremental innovation: The moderating role of technology management. Technovation, 33(6), 234-246.

Ostergaard, C. R., Timmermans, B., \& Kristinsson, K. (2011). Does a different view create something new? The effect of employee diversity on innovation. Research Policy, 40, 500-509.

Pandza, K., Wilkins, T. A., \& Alfoldi, E. A. (2011). Collaborative diversity in a nanotechnology innovation system: Evidence from the EU Framework Programme. Technovation, 31, 476-489.

Pelled, L. H., Eisenhardt, K. M., \& Xin, K. R. (1999). Exploring the black box: an analysis of work group diversity, conflict, and performance. Administrative Science Quarterly, 44, 1-28.

Pierce, J. R., \& Aguinis, H. (2013). The Too-Much-of-a-Good-Thing Effect in Management. Journal of Management, 39(2), 313-338.

Rodríguez, H., Fisher, E., \& Schuurbiers, D. (2013). Integrating science and society in European Framework Programmes: Trends in project-level solicitations. Research Policy, 42, 1126-1137.

Ruef, M., Aldrich, H. E., \& Carter, N. M. (2003). The structure of founding teams: homophily, strong ties, and isolation among US entrepreneurs. American Sociological Review, 68, 195-222.

Steffens, P., Terjesen, S., \& Davidsson, P. (2012). Birds of a feather get lost together: new venture team composition and performance. Small Business Economics, 39(3), 727-743.

Stirling, A. (2007). A general framework for analysing diversity in science, technology, and society. Journal of the Royal Society, Interface, 4, 707-719.

Ucbasaran, D., Lockett, A., Wright, M., \& Westhead, P. (2003). Entrepreneurial founder teams: Factors associated with member entry and exit (pp. 107-126). Winter: Entrepreneurship Theory and Practice.

Vanaelst, I., Clarysse, B., Wright, M., Lockett, A., Moray, N., \& S'Jegers, R. (2006). Entrepreneurial team development in academic spinouts: An examination of team heterogeneity. Entrepreneurship Theory and Practice, 30(2), 249-271.

Von Raesfeld, A., Geurts, P., Jansen, M., Boshuizen, J., \& Luttge, R. (2012). Influence of partner diversity on collaborative public R\&D project outcomes: A study of application and commercialization of nanotechnologies in the Netherlands. Technovation, 32(3), 227-233.

Webber, S., \& Donahue, L. (2001). Impact of highly and less job-related diversity on work group cohesion and performance: A meta-analysis. Journal of Management, 27, 141-162. 